\title{
An Integrated Control and Protection Scheme Based on FBSM-MMC Active Current Limiting Strategy for DC Distribution Network
}

\author{
Tao Zheng, Member, IEEE, Wenxuan Lv, Qiong Wu, Rui Li, Member IEEE, Xiaoxiao Liu, Student Member IEEE, \\ Chengqi Zhang, and Lie Xu, Senior Member, IEEE
}

\begin{abstract}
DC faults can easily lead to overcurrent in DC distribution networks; these faults pose serious threats to the safe operation of the system. The blocking of modular multilevel converters based on the full-bridge sub-modules (FBSM-MMC) is mostly utilized to cut off the fault current. However, the blocking causes short-term blackouts in the entire DC distribution network and there are presently no effective solutions to address this problem. In this study, an integrated control and protection scheme based on the FBSM-MMC active current limiting strategy is proposed. The project includes three stages: first, MMC active current limiting strategy is used to limit the output current of the converter to about 1.2 p.u. after the occurrence of the fault (Stage 1); next, faulty lines are identified based on the asynchronous zero-crossing features of the DC currents of the two ends of the line (Stage 2); then, a fault isolation scheme based on the cooperation of converters, DC circuit breakers, and high-speed switches is proposed to isolate the faulty line (Stage 3). The distribution network can restart quickly via control of the converters. Finally, the simulation of a four-terminal flexible DC distribution network in PSCAD/EMTDC demonstrates the effectiveness of the proposed integrated scheme.
\end{abstract}

Index Terms - Flexible DC distribution network, full-bridge sub-modules, converter active current limiting control, current zero-crossing detection, integrated control and protection scheme.

\section{INTRODUCTION}

$\mathrm{W}$ ith high penetration of distributed generation and directcurrent (DC) loads, the traditional alternating-current (AC) distribution network faces the problems like poor voltage regulation, power quality, voltage unbalance, feeder overloading, and reverse power-flow. The flexible DC distribution networks can be used to alleviate those problems, thanks to their advantages of improved voltage regulation, higher power handling capability, and lower feeder losses. [1] [2]. Currently, half-bridge modular multilevel converters (HB-MMCs) and full-bridge MMCs (FB-MMCs) are commonly employed in flexible DC distribution networks. Although the HB-MMCs

This work is supported in part by the Key Project of Smart Grid Technology and Equipment of National Key Research and Development Plan of China under grant 2016YFB0900600, and in part by the Technology Projects of State Grid Corporation of China under grant 521104180002. (Corresponding authors: Tao Zheng and Rui Li) have advantages of low power losses and capital costs, they cannot interrupt DC fault currents due to the free-wheeling diodes within the submodules (SMs). DC circuit breakers (DCCBs) must be used in HB-MMC systems to clear dc short circuit faults. On the contrary, FB-MMCs can block DC fault currents without the need for additional devices. Therefore, FBMMC technology constitutes an attractive choice for DC distribution network [3]. The hybrid MMC with FBSMs and HBSMs mixed in each arm is also proposed to block DC faults with reduced capital costs and losses compared to the FB-MMC [4][5]. The hybrid MMC is capable of generating the required negative voltage and remaining in operation during faults to actively inject fault current to the distribution network, in the same way as that of the FBSM-MMC. Therefore, the proposed protection scheme is applicable to the hybrid MMC [6] and the FBSM-MMC is taken as an example in this paper for simplicity.

Fault tolerance is an important aspect in the operation of flexible DC distribution networks. Symmetrical monopole FBMMCs have been most employed, in which the pole-to-pole fault may seriously damage the power converters and need to be isolated rapidly. The DC fault protection of a three-terminal MVDC demonstration project is introduced in [7], where two terminals based on HBSM-MMCs are protected by DCCBs while the other terminal based on the hybrid MMC with DC fault blocking capability is protected by the AC circuit breaker (ACCB). However, fault detection is not discussed. Various fault detection methods have been studied, e.g. traveling-wave based protection [8]-[11], transient high-frequency impedance comparison based protection [12], and directional pilot protection with over-current criteria [13], etc. However, these methods can only detect the faulty line and the fault clearance remains unclear.

Studies of fault active control for FB-MMC using terminal voltage control and terminal current control are discussed in [14] [15]. However, those strategies cannot detect the faulty line, and thus, it has to control all the MMCs in the network out of service to decouple the fault. The short-term power outage of the entire system severely damages the power supply reliability.

T. Zheng, W. Lv, Q. Wu, X. Liu and C. Zhang are with the Electrical and Electronic Engineering Department, North China Electric Power University, Beijing 102206, China(e-mail: zhengtao_sf@126.com; ncepulwx@163.com; ncepuwuqiong@163.com; m18811315622@163.com ;1417485189@qq.com).

R. Li and L. Xu are with the Department of Electronic and Electri-cal Engineering, University of Strathclyde, Glasgow, G1 1XW UK (email:rui.li@strath.ac.uk; lie.xu@strath.ac.uk). 
Therefore, an integrated control and protection scheme has to be proposed to clear the fault without affecting the healthy line. Especially for the DC distribution system with ring topology discussed in this paper, it calls for higher demands for the cooperation of protection and control, owing to the more complicated structure compared with the radial and hand-inhand topology networks [16] [17].

Currently, researches combining the active control of FB$\mathrm{MMC}$ and the protection have been conducted to enhance the fault ride-through ability of a flexible DC distribution network [18]-[22]. A control and protection scheme for transient fault is proposed in [18], however, it cannot realize the selective isolation in multi-terminal DC distribution networks, neither in the network with a ring topology. [19] proposed a control and protection scheme using a developed hybrid AC/DC relay to prevent the blackouts caused by cascading faults. However, the scheme is not suitable for the DC networks without the proposed hybrid AC/DC relay. In [20], the active control of VSC is introduced to limit the fault current actively in AC microgrid, but this strategy needs reactive compensation to improve the performance. In [21], the control of sub-modules in the transfer branch of a DCCB is used to differentiate instantaneous and permanent faults in DC lines before reclosing, rather than proposing a specific method to locate and isolate the DC fault. In [22], a voltage-error-dependent fault current injection is proposed to limit fault currents during faults and enable overcurrent fault detection and location. A low energy protection logic is proposed [23], where differential protection is adopted to identify the faulty line and selectively isolate the DC fault. However, the accuracy of the presented fault detection may be influenced by distributed capacitance.

As a result, the protection and control methods reported in the literature have not effectively integrated the functions for limiting fault currents, detecting faulty lines, and clearing faults. Thus, further investigation is required. The main contribution of this paper is to propose an integrated control and protection scheme in FBSM-MMC based flexible DC distribution networks. The proposed scheme consists of three stages: active current limiting control (Stage 1), fault identification based on asynchronous current zero-crossing features (Stage 2), and fault isolation based on the cooperation of the DC circuit breaker and high-speed switch (Stage 3). The three stages respectively achieve the abovementioned three functions.

The paper is organized as follows. Section II presents the integrated control and protection scheme, considering different operating stages. In Section III, the proposed scheme is verified through the simulation in PSCAD/EMTDC and assessed. Finally, Section IV draws the conclusions.

\section{INTEGRATED CONTROL AND PROTECTION SCHEME BASED ON FBSM-MMC ACTIVE CURRENT LIMITING CONTROL STRATEGY}

This study is based on a four-terminal DC distribution network [24], as shown in Fig. 1. $\mathrm{L}_{1}-\mathrm{L}_{4}$ represent the four DC lines. Each line is configured with a DCCB at one terminal and a high-speed switch (HSS) on the other terminal, corresponding to $\mathrm{CB}_{1}-\mathrm{CB}_{4}$ and $\mathrm{S}_{1}-\mathrm{S}_{4}$, respectively. For the convenience of discussion, the DCCB, HSS, and corresponding MMC of the converter station on the same bus are considered as a unit. For example, $\mathrm{CB}_{1}, \mathrm{~S}_{1}$, and $\mathrm{T}_{1}$ can be regarded as a unit. $\mathrm{T}_{1}-\mathrm{T}_{4}$ are all FBSM-MMC based symmetrical monopole converter stations, among which $\mathrm{T}_{1}$ operates in a DC voltage control and reactive power control mode, and other converters operate in the active and reactive power control mode.

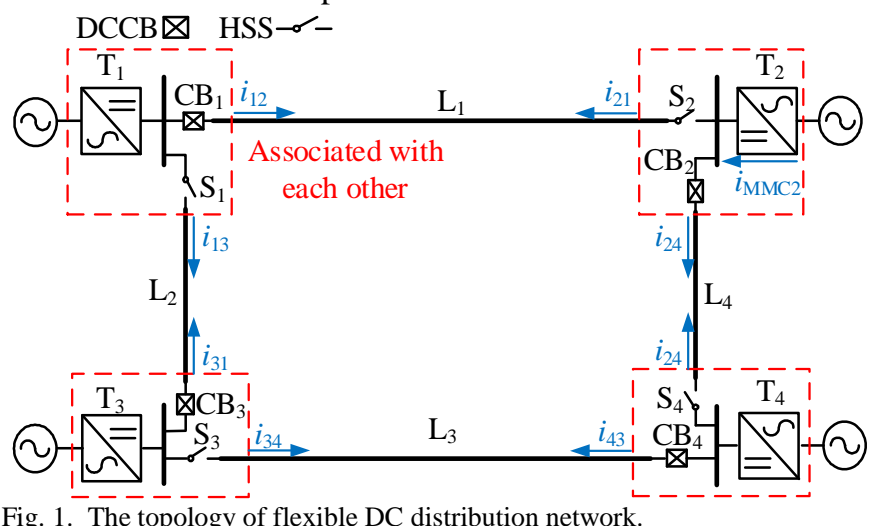

Fig. 1. The topology of flexible DC distribution network.

The symmetrical monopole topology is adopted for the considered DC distribution network, which does not experience significant overcurrent during pole-to-ground faults [12]. Therefore, only pole-to-pole DC fault is studied in this paper. The three-stage integrated control and protection scheme are analyzed in the following.

\section{A. Stage 1: FBSM-MMC-Based Active Current Limiting Control}

The internal structure of the FBSM-MMC in the converter station is shown in Fig. 2, where $I_{\mathrm{dc}}$ and $U_{\mathrm{dc}}$ are the output DC current and DC voltage of the MMC, $L_{\mathrm{arm}}$ is the arm inductance of MMC, and $L_{\mathrm{T}}$ is the leakage inductance of the transformer.

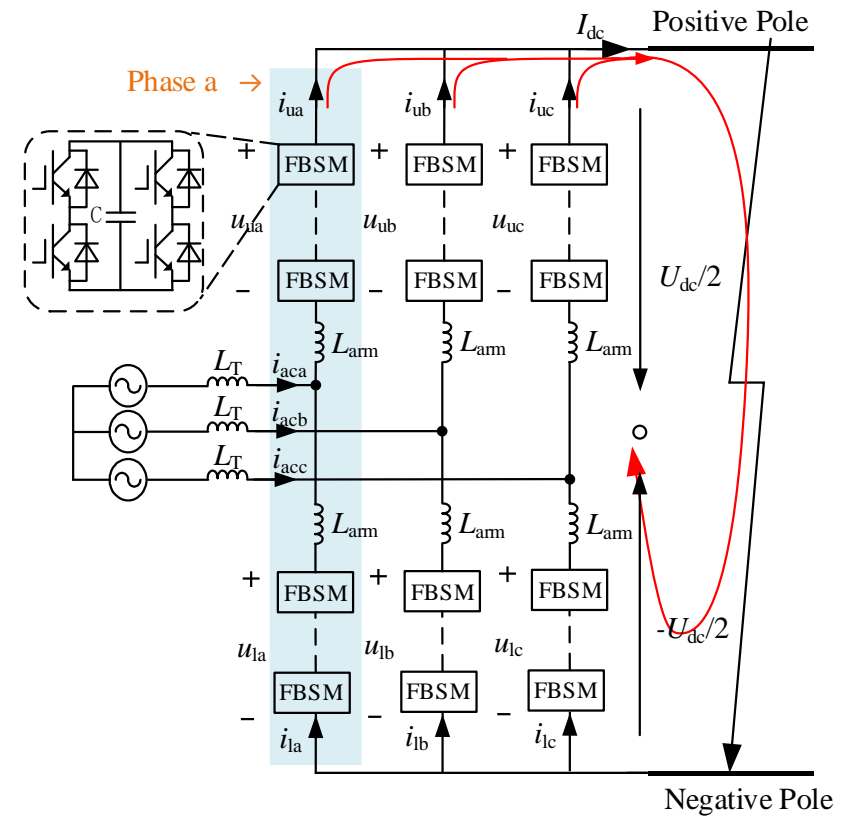

Fig. 2. Structure of FBSM-MMC.

The MMC control under normal operating conditions is presented in Fig. 3, where $L$ denotes the equivalent inductance and is equal to $L=L_{\mathrm{arm}} / 2+L_{\mathrm{T}}$. When the converter station adopts 
active power control, the outer controllers' strategy is changed from the DC voltage control to the active power control, as shown in the blue dashed frame in Fig. 3.

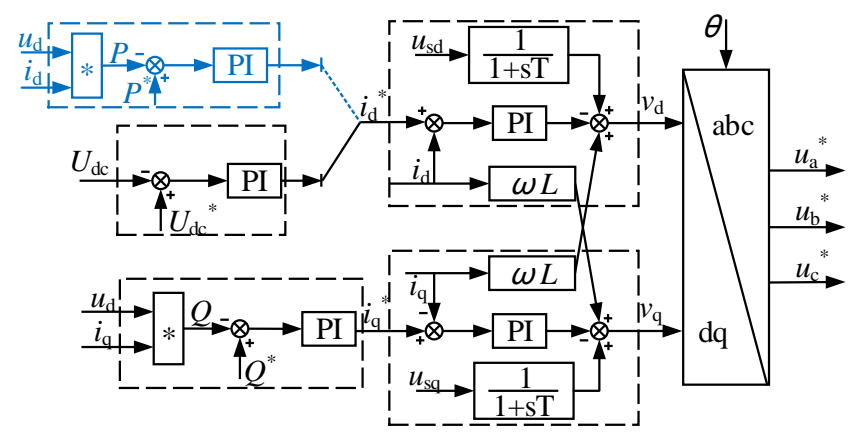

Fig. 3. Control structure of MMCs.

To suppress the second harmonic circulating current and to reduce power losses inside the converter, it is also necessary to add circulating current suppression control (CCSC), whose control theory is depicted in Fig. 4. The proposed active current limiting control is based on the CCSC.

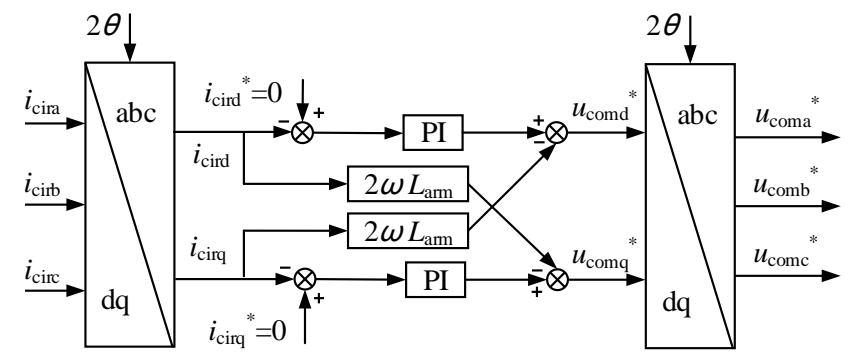

Fig. 4. Structure of CCSC control.

The reference value of the sub-module voltages of the upper and lower arms in each phase, $u_{\mathrm{u} j}{ }^{*}$ and $u_{\mathrm{lj}}{ }^{*}(j=\mathrm{a}, \mathrm{b}, \mathrm{c})$, can be calculated by the outputs of the outer controllers $\left(u_{j}{ }^{*}\right)$ and the voltage produced by the CCSC $\left(u_{\text {comj }}{ }^{*}\right)$, as shown in Fig. 5.

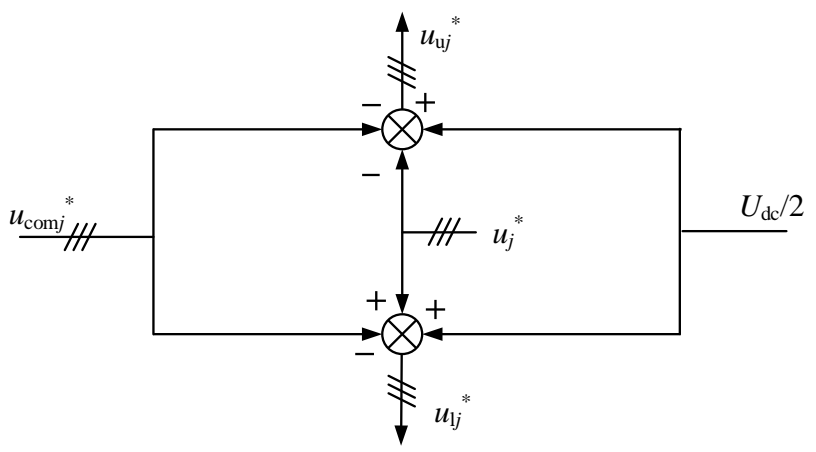

Fig. 5. Calculation of the reference value of MMC sub-module voltage.

Under normal operating conditions, the output DC current $I_{\mathrm{dc}}$ of a converter station is the sum of the currents of its internal three arms, that is

$$
I_{\mathrm{dc}}=i_{\text {cira }}+i_{\text {cirb }}+i_{\text {circ }}
$$

where, $i_{\text {cirj }}(j=\mathrm{a}, \mathrm{b}, \mathrm{c})$ is the circulating current component in each phase, which can be calculated by the upper- and lower-arm currents, as shown in (2).

$$
i_{\mathrm{cirj}}=\frac{\left(i_{\mathrm{u} j}+i_{\mathrm{lj}}\right)}{2}
$$

The single-phase equivalent structure is shown in Fig. 6, where $L_{\text {eq }}$ and $R_{\text {eq }}$ are equivalent inductance and resistance of phase $j(j=\mathrm{a}, \mathrm{b}, \mathrm{c})$. The voltage equation can be derived as (3).

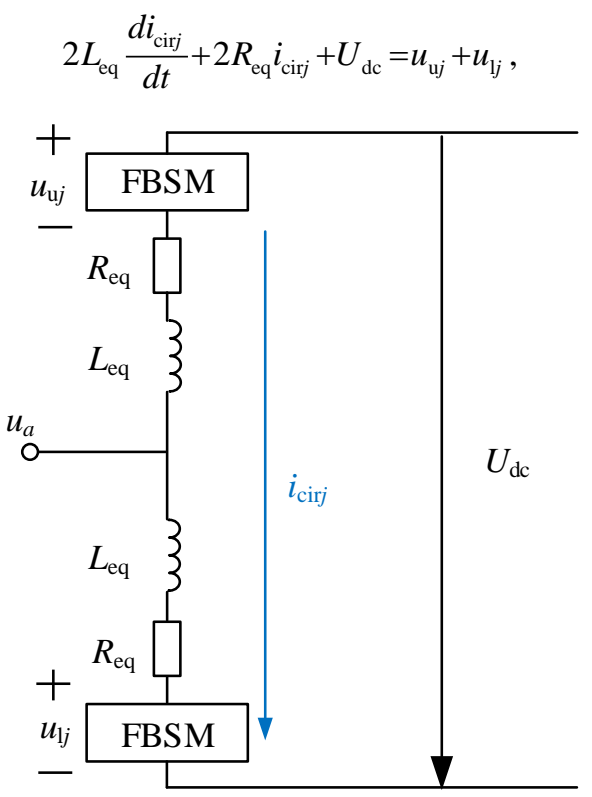

Fig. 6. Single-phase equivalent circuit

When a pole-to-pole fault occurs on the DC side, the DC voltage $U_{\mathrm{dc}}$ drops to 0 , (3) can be written as (4).

$$
2 L_{\mathrm{eq}} \frac{d i_{\mathrm{cir} j}}{d t}+2 R_{\mathrm{eq}} i_{\mathrm{cir} j}=u_{\mathrm{u} j}+u_{\mathrm{lj}}=u_{\mathrm{com} j},
$$

where $u_{\text {comj }}$ represents the voltage produced by the CCSC. By calculating the sum of $u_{\text {coma }}, u_{\text {comb }}$, and $u_{\text {comc }}$, the relationship between the output DC currents of the converter station and the bridge capacitor voltages are derived by:

$$
\begin{aligned}
& 2 L_{\mathrm{eq}} \frac{d}{d t}\left(i_{\text {cira }}+i_{\text {cirb }}+i_{\text {circ }}\right)+2 R_{\text {eq }}\left(i_{\text {cira }}+i_{\text {cirb }}+i_{\text {circ }}\right) \\
& =2 L_{\text {eq }} \frac{d I_{\mathrm{dc}}}{d t}+2 R_{\text {eq }} I_{\text {dc }}=u_{\text {coma }}+u_{\text {comb }}+u_{\text {comc }}
\end{aligned}
$$

Considering

$$
u_{\text {comz }}=u_{\text {coma }}+u_{\text {comb }}+u_{\text {comc }}
$$

The relationship between $I_{\mathrm{dc}}$ and $u_{\mathrm{comz}}$ can be obtained, as shown in (7).

$$
2 L_{\mathrm{eq}} \frac{d I_{\mathrm{dc}}}{d t}+2 R_{\mathrm{eq}} I_{\mathrm{dc}}=u_{\mathrm{comz}}
$$

Comparing (7) with (4), the output voltage $\left(u_{\mathrm{comz}}{ }^{*}\right)$ and the output reference voltages of the CCSC have the same characteristics, so it is reasonable to add $u_{\text {comz }}{ }^{*}$ determined by the fault current $\left(I_{\mathrm{dc}}\right)$ to $u_{\mathrm{com} j}{ }^{*}$ to control $I_{\mathrm{dc}}$ when a fault occurs [25]. The concrete method to limit a fault current is illustrated in Fig. 7. When a fault occurs, the control is put into use, and $u_{\mathrm{comz}}{ }^{*}$ depends on the difference between $I_{\mathrm{dc}}$ and the reference current $\left(I_{\text {dcree }}\right)$. Subsequently, $u_{\text {com } j}{ }^{*}$ obtained by $u_{\text {comz }}{ }^{*}$ and $u_{\text {com }}{ }^{*}$ is used to calculate the alternative reference valves of the submodule voltages. Through setting the reference value of $I_{\mathrm{dc}}{ }^{*}, I_{\mathrm{dc}}$ can be limited. Otherwise, $u_{\mathrm{comz}}{ }^{*}$ is equal to zero, and the control will not affect the normal operation of MMCs. 


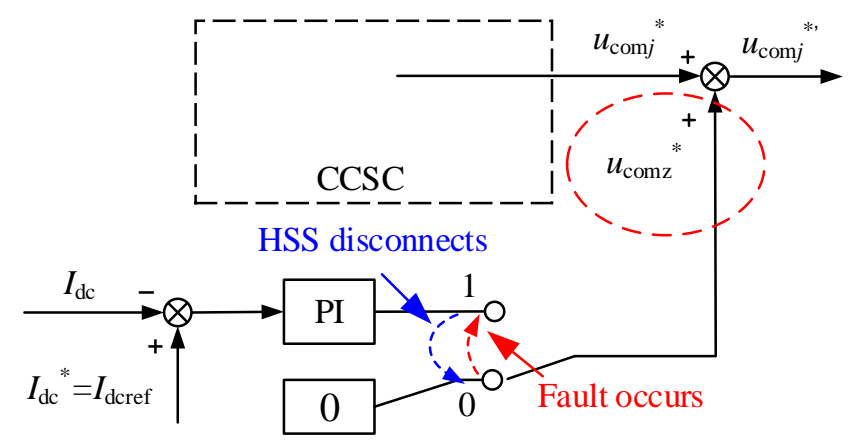

Fig. 7. Diagram of the current limiting control strategy of MMC.

$I_{\mathrm{dc}}$ is commonly limited to zero to avoid the overcurrent in the MMCs and ensure the fault clearance. However, the fault current features detected by the protection disappear quickly under this condition, which hampers the reliable detection of the faulty line [12]. In consequence, this study limits the postfault DC current of the converter station to 1.2 p.u., i.e. $I_{\text {dcref }}$ is set as 1.2 p.u., comprehensively considering the overcurrent level that the system can withstand and ensuring obvious fault features that the faulted line can be detected in the following stage 2.

\section{B. Stage 2: Fault Identification Based on Asynchronous Current Zero-Crossing Features}

After limiting the post-fault currents, a fault identification method based on the asynchronous zero-crossing features of the currents at both ends of the faulty line is analyzed in the following. Moreover, no-load operation condition and the impact of fault resistance are considered to discuss the correctness of the proposed method.

1) Asynchronous zero-crossing features of currents DCCB区 HSS $-\sigma$

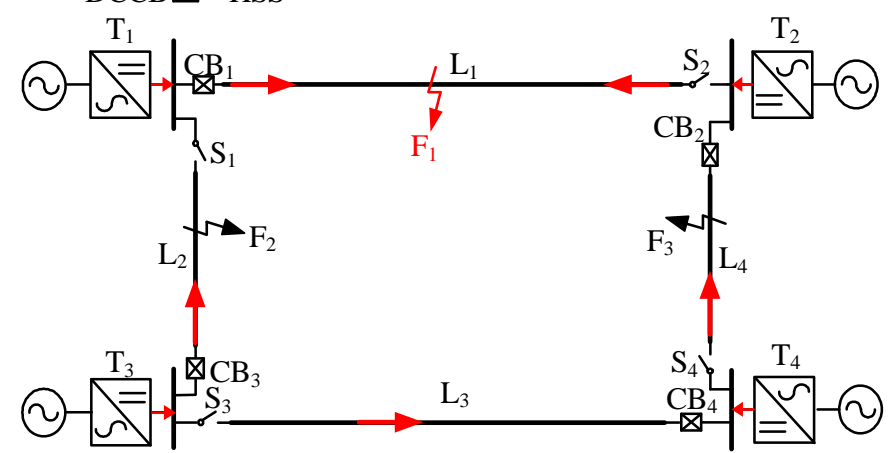

Fig. 8. Fault currents when a fault occurs at $F_{1}, F_{2}$, or $F_{3}$.

Fig. 8 provides the fault current distribution when a pole-topole DC fault occurs at $F_{1}$, as well as three possible fault locations. For the DC line $\mathrm{L}_{1}$, the fault $\mathrm{F}_{1}$ is an internal fault, and the faults $F_{2}$ and $F_{3}$ are external faults. When a fault occurs, all the fault currents flow from the converter station to the fault point. As shown in Fig. 8, all the currents flow into $F_{1}$ after the fault.

Fig. 9 indicates the direction change of the fault current of $\mathrm{L}_{1}$ when faults $F_{1}-F_{3}$ occur. In Fig. 9, the blue solid lines indicate the load current direction, and the red dashed lines show the trend of the post-fault currents. $I_{1} \& I_{\mathrm{f} 1}, I_{2} \& I_{\mathrm{f} 2}$ are the pre-fault
\& post-fault currents flowing through $\mathrm{CB}_{1}$ and $\mathrm{S}_{2}$. As shown in Fig. 9 (a), $I_{\mathrm{f} 1}$ is opposite to $I_{1}$ when the fault $\mathrm{F}_{1}$ occurs, and thus the zero-crossing of $I_{\mathrm{f} 1}$ must occur. On the contrary, $I_{\mathrm{f} 2}$ flows through $S_{2}$ in the same direction as $I_{2}$, which indicates the nonzero-crossing in $I_{\mathrm{f} 2}$. In short, the zero-crossing of the currents at both ends of the faulty line is asynchronous. However, when the fault $\mathrm{F}_{2}$ or $\mathrm{F}_{3}$ occurs, the zero-crossing phenomena are different, as shown in Figs. 9 (b) and (c). In Fig. 9 (b), the direction of the fault current indicates non-zero-crossing in $I_{\mathrm{f} 1}$ and $I_{\mathrm{f} 2}$, while in Fig. 9 (c), the directions of the fault current and the load current are opposite to each other, and the zero-crossing may occur in both $I_{\mathrm{f} 1}$ and $I_{\mathrm{f} 2}$.

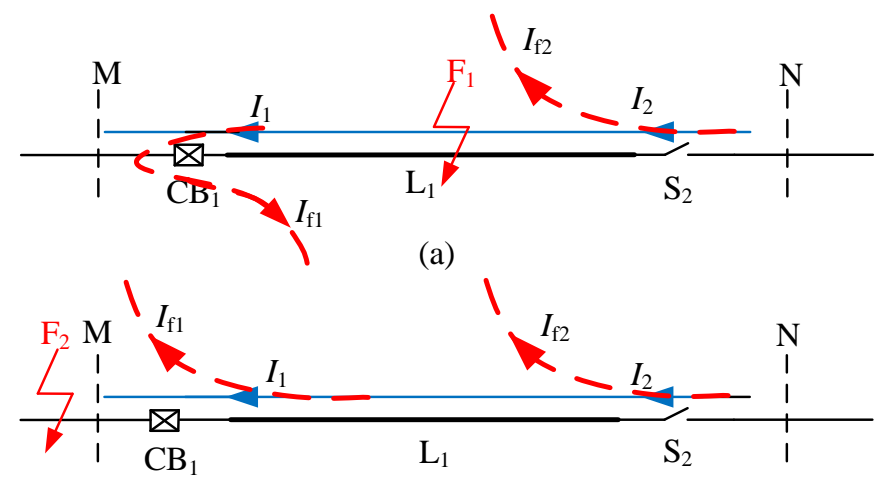

(b)

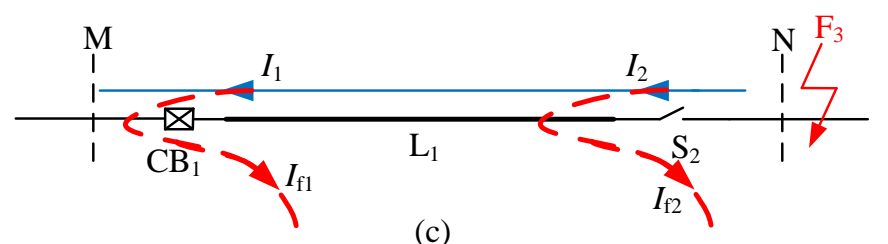

Fig. 9. Flow direction of the fault current in line $\mathrm{L}_{1}$ with (a) internal fault at $\mathrm{F}_{1}$, (b) external fault on $\mathrm{M}$ side, and (c) external fault on $\mathrm{N}$ side.

In conclusion, when a pole-to-pole fault occurs, the zerocrossing features in the currents at both ends of the faulty line are different, while they are the same in the healthy line: currents at both ends demonstrate zero-crossing or non-zerocrossing features synchronously. Depending on such fault characteristics, faulty lines can be distinguished from healthy lines precisely.

2) The influence of no-load operation

If the line operated at no-load condition, it may be inapplicable to identify faults using the current zero-crossing features at two ends of the line, since the pre-fault current is always equal to zero. Adding a current offset value $(\Delta I)$ in the pre-fault current may solve the above problem. This means that the pre-fault current at one end of the no-load line is $+\Delta I$, while that at the other end is $-\Delta I$, as shown in Fig. 10 (a). The positive direction of the current is supposed to be the same as that of the load current (blue solid lines) in Fig. 9.

When an internal fault occurs at $\mathrm{L}_{1}$, as shown in Fig. 10 (b), the current at $\mathrm{CB}_{1}$ is equal to $I_{\mathrm{f} 1}+\Delta I$ and shows non-zerocrossing features after the fault. The current at $\mathrm{S}_{2}$ is equal to $I_{\mathrm{f} 2}$ $-\Delta I$, and the current zero-crossing may occur. As a result, the asynchronous zero-crossing feature of the currents at both ends of the faulty line is created, and the faulty line can be detected reliably. 


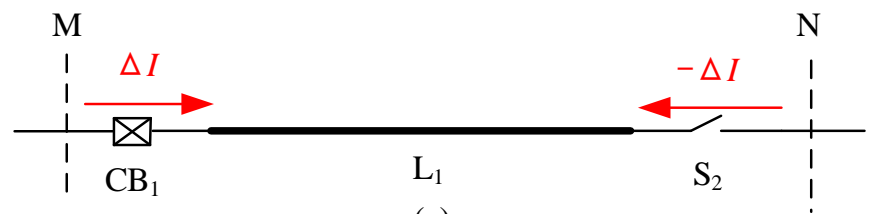

(a)

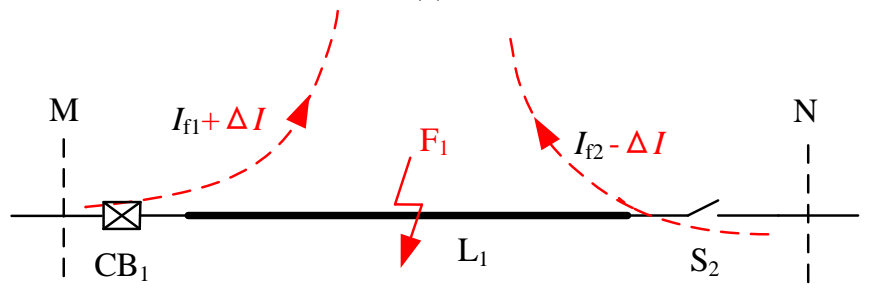

(b)

Fig. 10. Current of no-load line $\mathrm{L}_{1}$ when is $\Delta I$ added: (a) pre-fault condition; (b) internal fault condition.

3) Influence of fault resistances

In the conventional control scheme, if the fault current is less than the load current in the event of high impedance faults, the currents at both ends of the faulty line may do not change direction, as illustrated in Fig. 11 (yellow arrows). However, in the proposed scheme, the FBSM-MMC actively injects current into the fault and thus, the current at one end of the faulty line is forced to cross zero while the other does not, as seen in Fig. 11 (green arrows). The faulty line hence can be accurately identified in the proposed protection scheme.

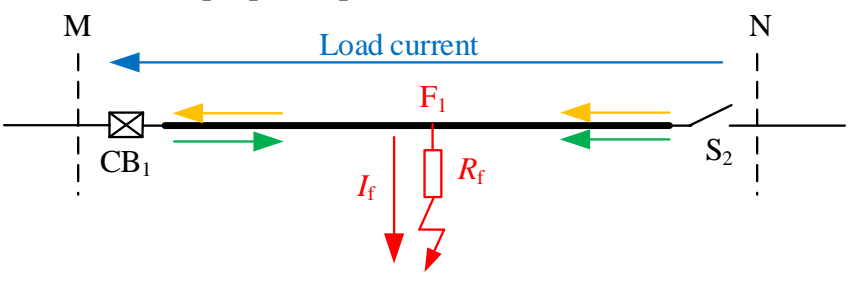

Conventional scheme —_ Proposed scheme -

Fig. 11. Comparison of current direction between the conventional and proposed schemes during high impedance faults.

\section{Stage 3: Fault Isolation Based on the Cooperation of DCCB and HSS}

After the faulty line is identified through stage 2, the faulty line should be isolated as soon as possible. Although the fault isolation is easier to realize when the DCCBs are equipped at both ends of the line, the scheme has poor economics. Therefore, further research on isolating the fault based on economical DCCB configuration is required, which will be analyzed in this section.

1) Fault isolation scheme

At present, electrical devices that can be used to isolate the fault mainly are DCCB and HSS [26]. In order to reduce the number of DCCBs equipped, HSSs are used to replace some DCCBs in the network. Since HSS itself does not have the ability of arc suppressing, it has to be coordinated with other devices to fast isolate the fault [27] [28]. Since the DC current can be regulated by MMC active current limiting control, the fault isolation scheme presented in this paper utilizes $\mathrm{MMC}$ active current limiting control and the cooperation of DCCB and HSS. Such a scheme realizes the optimization of DCCB configuration and conserves the cost of network construction. A detailed scheme is described below.

Supposing the fault $\mathrm{F}_{1}$ occurs, the FB-MMCs immediately switch to the DC current control mode after fault detection to limit the output DC current at 1.2 p.u. Subsequently, the faulty line will be detected according to the asynchronous zerocrossing features of the currents at both ends of the faulty line. After the fault current limitation, $\mathrm{CB}_{1}$ can cut off the fault current more easily and reliably, since the active control decreases the fault current from several tens of times the rated current to approximately two to three times. However, $S_{2}$ needs to coordinate with $\mathrm{CB}_{2}$ and $\mathrm{T}_{2}$ to open, since it can only be disconnected when fault current crosses zero. The specific cooperating method is illustrated in Fig. 12: first, disconnect circuit breaker $\mathrm{CB}_{2}$; then, change the control strategy of MMC in converter station $\mathrm{T}_{2}$ and reduce its output current to zero; finally, disconnect $\mathrm{S}_{2}$, and thus accomplishing the faulty line isolation.

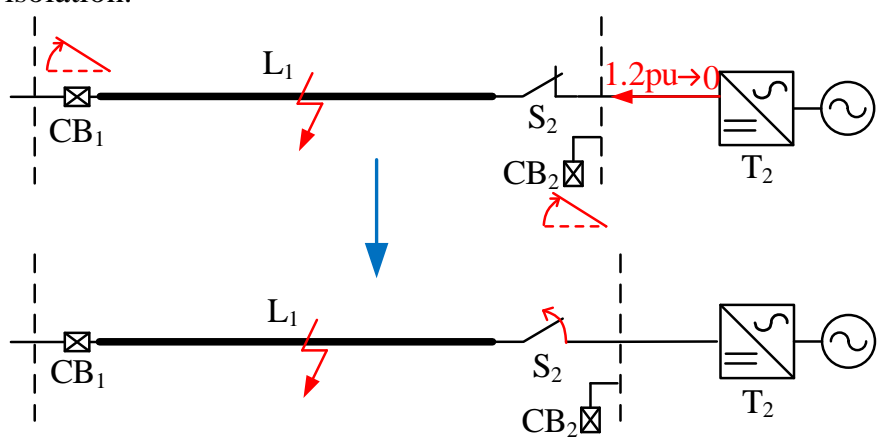

Fig. 12. The action of protection device at both ends of line $\mathrm{L}_{1}$.

The characteristics of the fault isolation scheme based on DCCB and HSS are summarized as follows:

- For each line in the DC distribution network, only one end needs to be equipped with DCCB. Compared to the scheme in need of DCCB at both ends, the number of DCCBs is reduced by half. Besides, the cost of DCCB production is reduced due to the fault current has been limited by active control in Stage 1. Therefore, the cost of construction is saved considerably.

- $\quad$ For the pure HSS scheme, where only the HSS is equipped at each end of DC line, the entire DC network needs to be de-energized to open HSSs for fault isolation, leading to long interruption of power transmission. Differently, in the proposed scheme, the DCCBs open after fault detection to fast partition the DC network, and hence the power transmission of the healthy part can fast restore. The impact of the fault on the system is thus minimized in the proposed protection arrangement.

- The only action required when the faulty line is cut off is to control the output current of the converter station at the HSS side to zero.

2) Fault restoration scheme

After the fault isolation, power supplied by converter station $\mathrm{T}_{2}$ to line $\mathrm{L}_{4}$ needs to be restored. Once the disconnection of $\mathrm{S}_{2}$ is completed, a signal will be sent to each converter to switch from the current limiting control mode to normal operating 
mode. $\mathrm{CB}_{2}$ will also be closed to restore electric power supplied by $\mathrm{T}_{2}$ to $\mathrm{L}_{4}$. In order to set up DC voltage quickly, the reference value of DC voltage control is set as the rated DC voltage directly. If the active power $P_{\mathrm{dc}}$ injected into the DC distribution network is large, according to (8), an overcurrent will be caused during the DC voltage recovery process.

$$
I_{\mathrm{dc}}=\frac{P_{\mathrm{dc}}}{U_{\mathrm{dc}}}
$$

Therefore, the active power reference should increases to its rated value linearly over time to avoid the overcurrent, as shown in Fig. 13.

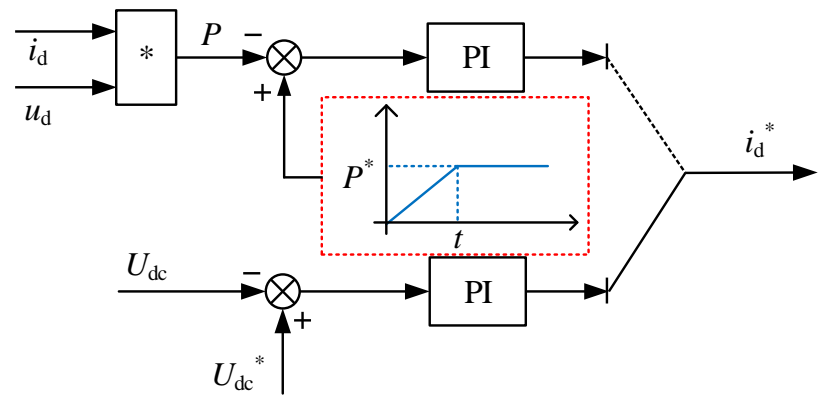

Fig. 13. The linear increasing process of the reference value of active power control.

\section{Flowchart of Protection and Fault Isolation Scheme}

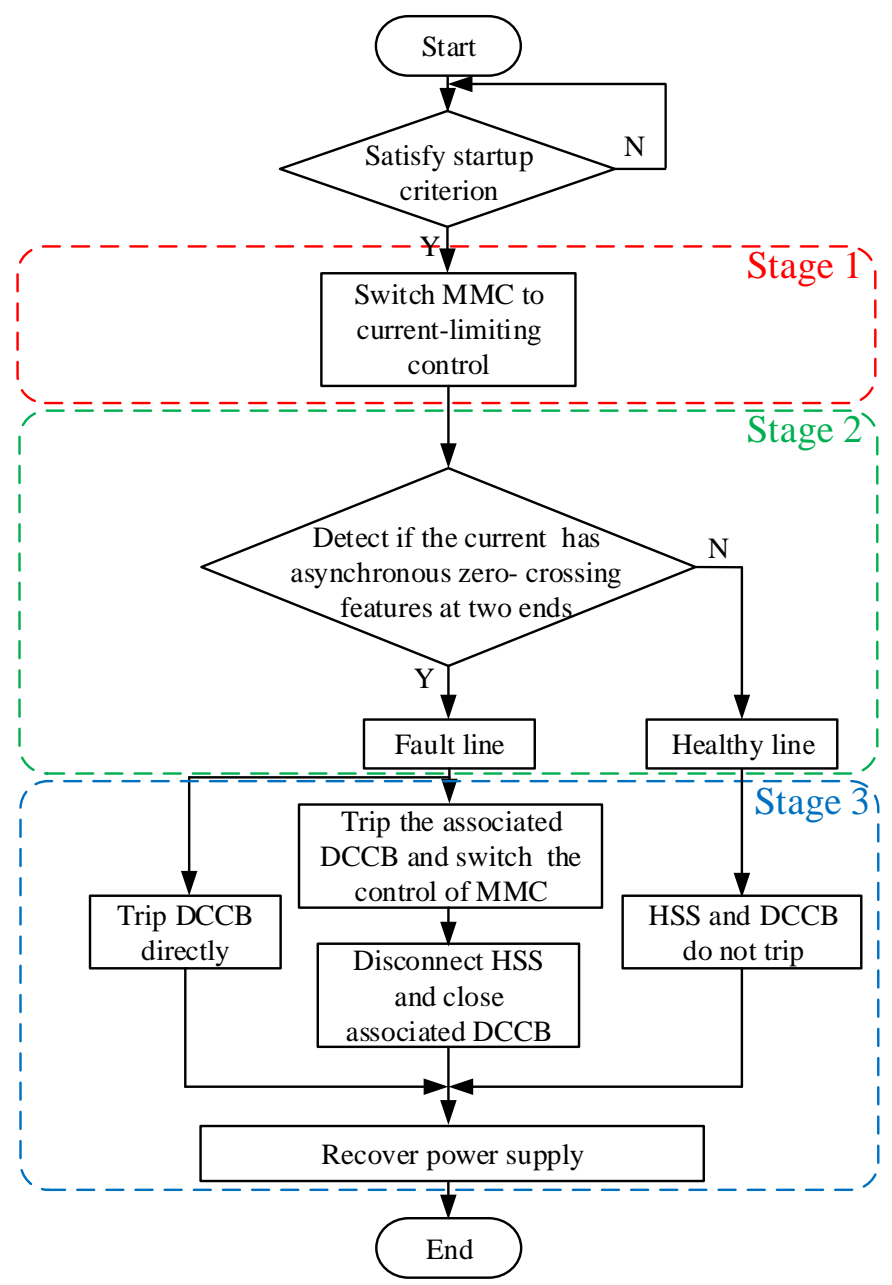

Fig. 14. Flowchart of integrated control and protection scheme.
As a summation of the analysis above, Fig. 14 shows the flow chart of the integrated control and protection scheme proposed in this paper. In this scheme, the start-up of FB-MMC active current limiting control is accomplished by tracking the rate of change of DC voltage [12]. After the fault occurs, the voltage of the DC network decreases rapidly. If the changing rate of DC voltage $d u / d t$ satisfies the start-up criterion, the MMC active current limiting control will be put into service. Subsequently, the faulty line is detected according to the asynchronous zerocrossing features of the post-fault currents at both ends of the lines. Finally, the MMC, DCCB, and HSS are cooperated to isolate the faulty line.

As a consequence, the integrated scheme proposed in this paper solves the technical difficulty of short-term power outages in the whole system caused by FB-MMC blocking after the fault in FB-MMC based flexible DC distribution networks, by means of the coordination of 'active current limiting control', 'faulty line identification', and 'fault isolation'.

\section{Simulation VerificATION}

The simulation model of flexible DC distribution network is built in PSCAD/EMTDC, as shown in Fig. 1. Converter stations at four terminals are all constructed with FBSM-MMC topology.

TABLE I.

PARAMETERS OF THE MMCS

\begin{tabular}{cc}
\hline \hline Parameter & Value \\
\hline Voltage of DC distribution lines & $\pm 10 \mathrm{kV}$ \\
Voltage of AC grid & $110 \mathrm{kV}$ \\
Rated power of converter devices & $4 \mathrm{MW}$ \\
Turn ratio of the converter transformer & $110 / 10 \mathrm{kV}$ \\
\hline \hline
\end{tabular}

TABLE. II.

PARAMETERS OF THE DC LINES [29]

Parameter

Value

\begin{tabular}{cc}
\hline Line model type in PSCAD & $\begin{array}{c}\text { Frequency-dependent } \\
\text { (phase) Model } \\
4 \times 20 \mathrm{~km}\end{array}$ \\
Length of DC distribution line & $0.742 \mathrm{mH} / \mathrm{km}$ \\
Inductance of DC distribution lines & $0.0318 \Omega / \mathrm{km}$ \\
Resistance of DC distribution lines & $0.012258 \mathrm{uF} / \mathrm{km}$ \\
Capacitance of DC distribution lines & \\
\hline \hline & TABLE. III. \\
PARAMETERS OF THE DCCBS [30] & Value \\
\hline \hline Operating time & $2 \mathrm{~ms}$ \\
Rated voltage & $\pm 10 \mathrm{kV}$ \\
Breaking current & $2 \mathrm{kA}$ \\
Short-time withstand current & $20 \mathrm{kA} / 1 \mathrm{~s}$ \\
Peak withstand current & $50 \mathrm{kA}$ \\
\hline
\end{tabular}

The detailed parameters of the MMCs, DC lines and DCCBs 
in the tested flexible DC distribution networks are list in Table I, Table II, and Table III, respectively. The HSS is modeled as an ideal switch which can only be operated at zero current. A delay time of $2 \mathrm{~ms}$ is introduced in the operation of the ideal switch to model the mechanical time delay [31]. Shown below is the verification of the integrated control and protection scheme put forward in this paper, in combination with a simulation model.

\section{A. Stage 1: MMC Active Current Limiting Control}

During a pole-to-pole fault, the measured magnitude of output DC current $\left(i_{\mathrm{MMC} 1}\right)$ of the converter station with and without current limiting control is displayed in Fig. 15. The fault occurred at $t=0 \mathrm{~ms}$, and the current limiting control was activated at $t=0.5 \mathrm{~ms}$ [32].

From the blue line shown in Fig. 15, the current surges after the fault occurs, and severe overcurrent appear within $10 \mathrm{~ms}$ since there is no MMC active current limiting control in service. However, the fault current is limited considerably as the green line shows. Hence, MMC active current limiting control significantly limits output DC current of the converter station after the fault.

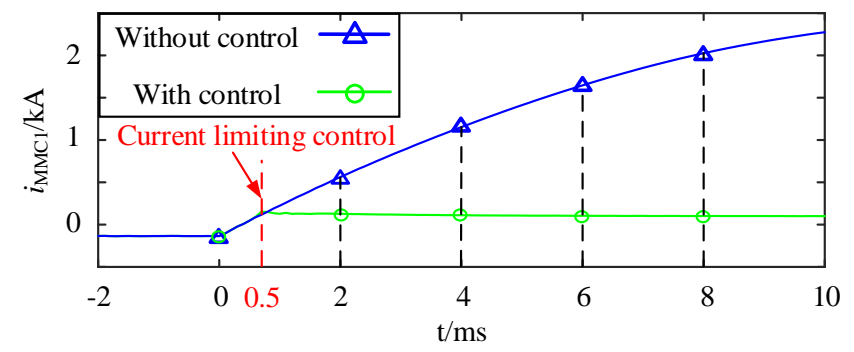

Fig. 15. DC current of MMC $I_{\mathrm{dc} 1}$ with and without MMC current limiting control.

The capacitor voltages of FBSMs fluctuate around the rated value and their peaks are well controlled below 1.1 p.u. [25] during the fault, as shown in Fig. 16 (a). The upper and lower arm currents exhibit disturbance during the fault but are less than 2 p.u. [25] and thus, the FBSM-MMC can remain in operation during the fault and actively inject fault currents to the DC network, as displayed in Fig. 16 (b) and (c). In the proposed method, the DC current is slighted increased to 1.2 p.u. but, due to the reduced transmitted power, the three-phase $\mathrm{AC}$ currents are reduced and balanced during the fault, as shown in Fig. 16 (d). Therefore, the arm currents do not significantly increase as observed in Fig. 16 (b) and the IGBTs are not exposed to substantial current stress.
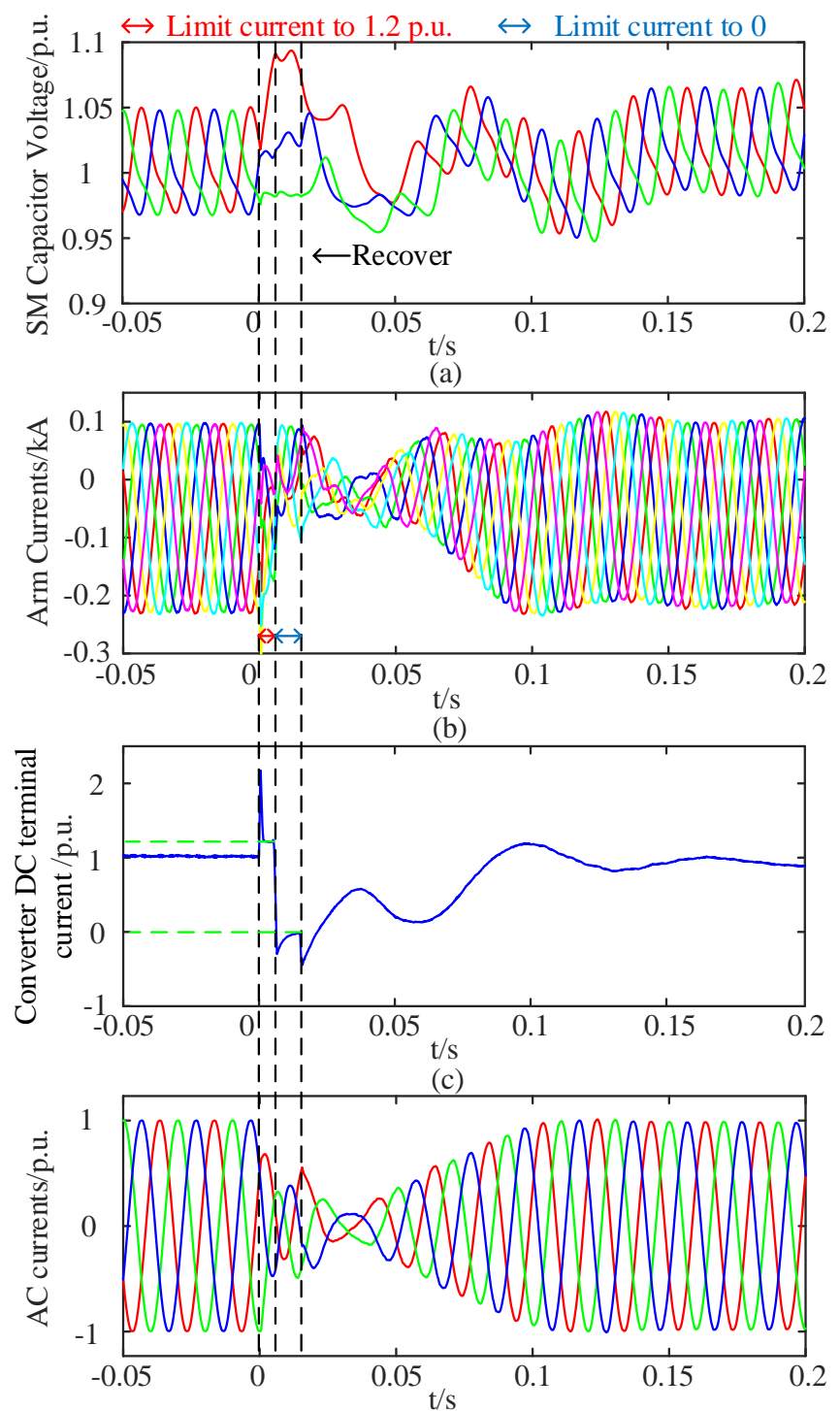

(d)

Fig. 16. Waveforms of the converter T2. (a) average SM capacitor voltages of the three-phase upper arms, (b) upper and lower arm currents, (c) converter DC terminal current and (d) three-phase AC currents.

\section{B. Stage 2: Fault Identification Based on Asynchronous Current Zero-Crossing Features}

When fault $F_{1}$ occurs, fault currents in $L_{1}$ to $L_{4}$ are demonstrated in Fig. 17, wherein $i_{12}$ is the current flowing from $T_{1}$ to $T_{2}$ in $L_{1}, i_{21}$ is the current flowing from $T_{2}$ to $T_{1}$, and so forth.

Fig. 17 shows that the current zero-crossing point only occurs at one end of the faulty line $L_{1}$. Both ends of healthy line $L_{2}$ and $\mathrm{L}_{3}$ performs non-zero-crossing features, and yet, the synchronous zero-crossing point is observed in the healthy line $\mathrm{L}_{4}$ during the entire process. Therefore, the faulty line $\mathrm{L}_{1}$ is detected. The MMC active current limiting control strategy discussed in this paper maintains an output DC current of the converter station at approximately 1.2 p.u. However, in Fig. 17, two ends of $L_{1}$ experience the fault current surging to approximately 4 p.u. The reason for this phenomenon is that currents $i_{12}$ and $i_{21}$ not only consist of the post-fault currents of converter stations $T_{1}$ and $T_{2}$, but also include the feeding 
currents from converter stations $\mathrm{T}_{3}$ and $\mathrm{T}_{4}$. Compared with the overcurrent caused by blocking, the fault current is not only well limited but also exhibit obvious fault features, which helps with the right choice of protection.

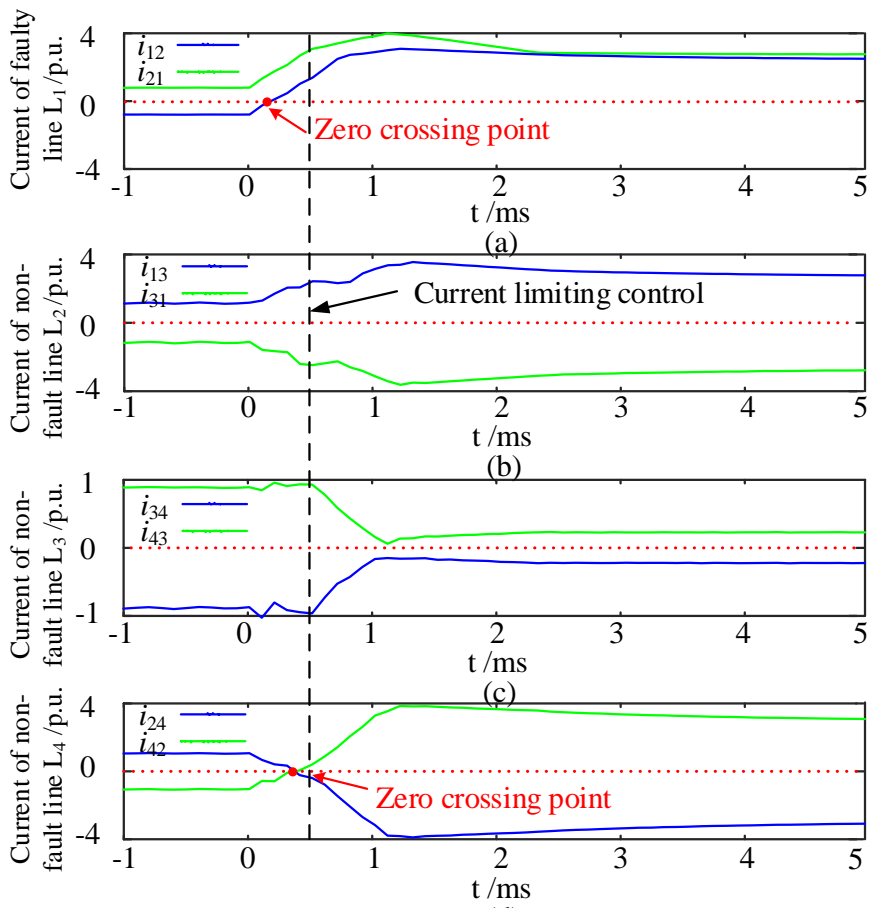

(d)

Fig. 17. Fault currents at each line when a fault occurs at $F_{1}$ : (a) $L_{1}$, (b) $L_{2}$, (c) $\mathrm{L}_{3}$, and (d) $\mathrm{L}_{4}$.

\section{Stage 3: Fault Isolation Based on the Cooperation of $D C C B$ and $H S S$}

Similarly, to verify the efficiency of the fault isolation scheme mentioned in subsection III. $C$., a pole-to-pole DC fault $\mathrm{F}_{1}$ was simulated. The currents flowing through $\mathrm{CB}_{1}$ and $\mathrm{S}_{2}$ are shown in Fig. 18.

The current at $\mathrm{CB}_{1}$ in $\mathrm{L}_{1}$ is shown in Fig. 18 (a). It is evident in the figure that within $5 \mathrm{~ms}$ after fault occurrence, the fault current is well-limited thanks to MMC active current limiting control. In this situation, requirements for breaking the capacity of $\mathrm{CB}_{1}$ are lower in comparison with the case where there is no active current limiting control. At $5 \mathrm{~ms}$, faulty line identification is accomplished and the current at that point damps to 0 spontaneously from tripping $\mathrm{CB}_{1}$.

Since $\mathrm{MMC}_{2}$ in converter station $\mathrm{T}_{2}$ needs to cooperate with $\mathrm{CB}_{2}$ to disconnect $\mathrm{S}_{2}$, the output DC current $i_{\mathrm{MMC} 2}$ in the converter station and current $i_{24}$ at $\mathrm{CB}_{2}$ are shown in Fig. 18 (b). During $0-5 \mathrm{~ms}$ after fault happens, MMC active current limiting control restrains $i_{\mathrm{MMC} 2}$ and fault current at $\mathrm{CB}_{2}$ in specific ranges, with respect to the reference 1.2 p.u. of output $\mathrm{DC}$ current of the converter station. At $5 \mathrm{~ms}$, the associated $\mathrm{CB}_{2}$ is tripped, and $I_{\mathrm{dc}}{ }^{*}$ is adjusted to 0 . The current flowing through $\mathrm{S}_{2}$ drops to 0 quickly as shown in Fig. 18 (b).

Fig. 18 (c) demonstrates the waveform of $i_{21}$ flowing through switch $\mathrm{S}_{2}$. Current $i_{21}$ damps to 0 rapidly right after the disconnection of $\mathrm{CB}_{2}$ and $I_{\mathrm{dc}}{ }^{*}$ changes to 0 . Then, $\mathrm{S}_{2}$ is disconnected. Since $\mathrm{CB}_{1}$ opposite to the faulty line has already been switched off, the fault is thus isolated.
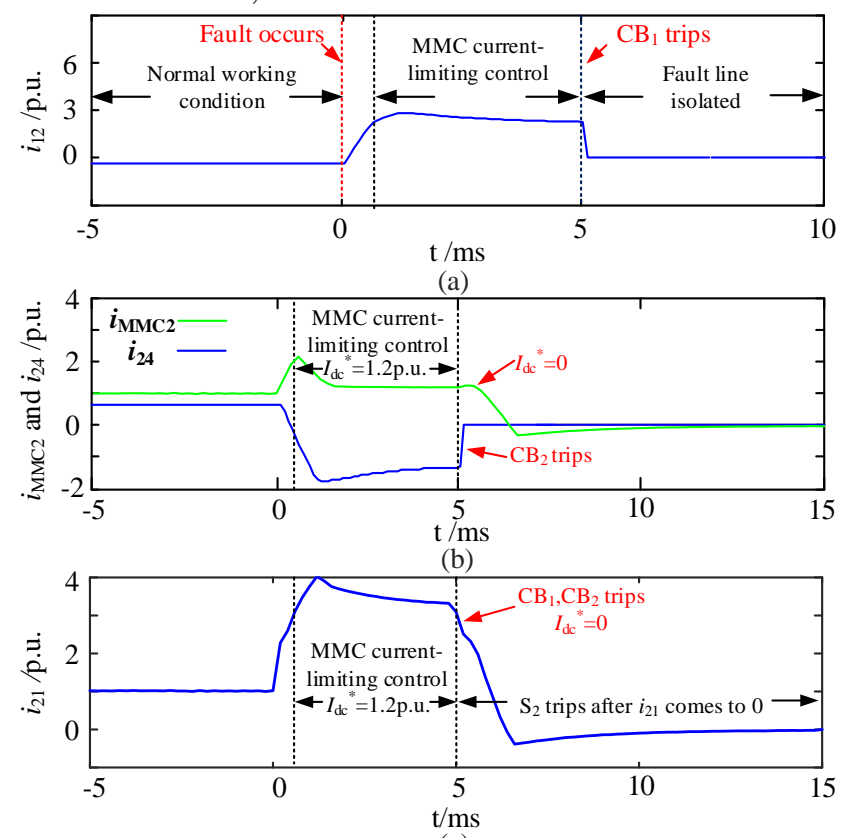

(c)

Fig. 18. Waveforms of fault currents during stage 3: (a) fault current $i_{12}$., (b), fault currents $i_{\mathrm{MMC} 2}$ and $i_{24}(\mathrm{c})$ fault current $i_{21}$
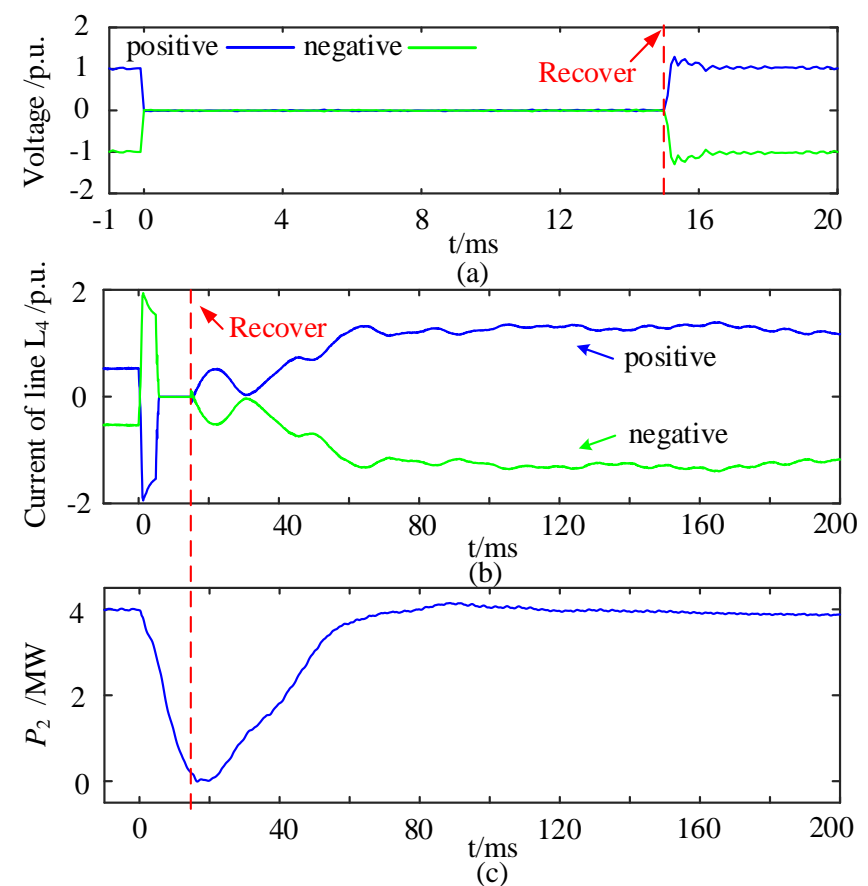

Fig. 19. Waveforms of $\mathrm{L}_{4}$ and converter $\mathrm{T}_{2}$ : (a) voltage of line $\mathrm{L}_{4}$; (b) current of line $\mathrm{L}_{4}$ and (c) active power of converter $\mathrm{T}_{2}$.

Considering the time delay of DCCB and HSS [30], DC distribution network recovers at $15 \mathrm{~ms}$ after the fault occurs. The current, voltage of line $\mathrm{L}_{4}$ and active power of converter station $T_{2}$ during the recovery process are shown in Fig. 19. After the isolation of the faulty line, the DC distribution network could build up voltage during a few milliseconds and resume active power supplied by converter station $\mathrm{T}_{2}$ to line $\mathrm{L}_{4}$ in approximately $100 \mathrm{~ms}$. 


\section{Influence of Additional Branch on the Proposed Protection Scheme}

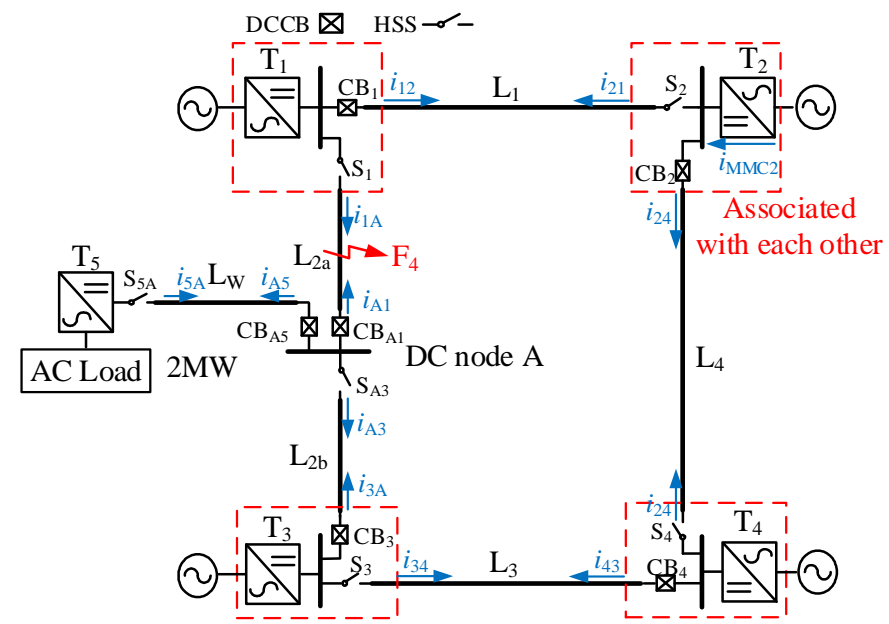

Fig. 20. A new topology of $\overline{D C}$ distribution network with a branch line connected to an AC load.

To verify the proposed scheme, an additional branch line $\mathrm{L}_{\mathrm{W}}$ is added to the tested DC network to supply a $2 \mathrm{MW}$ AC load through the FBSM-MMC $\mathrm{T}_{5}$, as illustrated in Fig. 20. The DCCB $\mathrm{CB}_{\mathrm{A} 5}$ and HSS $\mathrm{S}_{5 \mathrm{~A}}$ are equipped at each end of branch line $\mathrm{L}_{\mathrm{W}}$, and a similar protection arrangement has also be applied at the DC lines $\mathrm{L}_{2 \mathrm{a}}$ and $\mathrm{L}_{2 \mathrm{~b}}$.
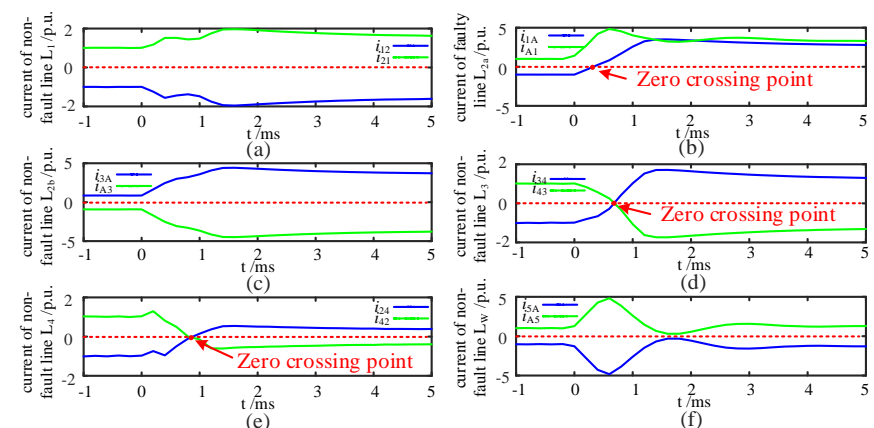

Fig. 21. Fault currents during DC fault $\mathrm{F}_{4}$ at each end of the line: (a) $\mathrm{L}_{1}$, (b) $\mathrm{L}_{2 \mathrm{a}}$, (c) $\mathrm{L}_{2 b}$, (d) $\mathrm{L}_{3}$, (e) $\mathrm{L}_{4}$ and (f) $\mathrm{L}_{\mathrm{W}}$.

To further confirm the validity of the proposed protection scheme, a pole-to-pole DC fault $\mathrm{F}_{4}$ is applied at the line $\mathrm{L}_{2 \mathrm{a}}$. After fault occurrence, in addition to converters $\mathrm{T}_{1}-\mathrm{T}_{4}$, the converter $\mathrm{T}_{5}$ at the branch line also actively limits the $\mathrm{DC}$ fault current to 1.2 p.u, as displayed in Fig. 21 (f). The current zerocrossing point occurs at only one end of the faulty line $\mathrm{L}_{2 \mathrm{a}}$, while no zero-crossing or synchronous zero-crossing is observed for the healthy lines $\mathrm{L}_{1}, \mathrm{~L}_{2}, \mathrm{~L}_{3}$ and $\mathrm{LW}_{\mathrm{w}}$, as displayed in Fig. 21 (a) and (c)-(f). According to such asynchronous zerocrossing characteristics of fault lines, the DCCB $\mathrm{CB}_{1}$ and $\mathrm{CB}_{\mathrm{A} 1}$ are thus tripped to fast partition the DC network. Then the converter $\mathrm{T}_{1}$ reduces its $\mathrm{DC}$ terminal current to zero and hence the HSS $S_{1}$ is opened at zero current to completely isolate the fault.

Similarly, if the fault occurs at the line $\mathrm{L}_{2 \mathrm{~b}}$, the DCCB $\mathrm{CB}_{3}$, $\mathrm{CB}_{\mathrm{Al}}$, and $\mathrm{CB}_{\mathrm{A} 5}$ will trip and then the HSS $\mathrm{S}_{\mathrm{A} 3}$ can be disconnected. For the fault at the line $\mathrm{L}_{\mathrm{DC}}, \mathrm{CB}_{\mathrm{A} 5}$ will trip and then $\mathrm{S}_{5 \mathrm{~A}}$ is disconnect after the converter $\mathrm{T}_{5}$ actively reduces its DC terminal current to zero. The faults that occur at other lines can also be similarly detected and isolated using the proposed arrangement.

\section{CONCLUSION}

This paper proposes an integrated control and protection scheme based on MMC active current limiting strategy for DC distribution networks. The main contributions are as follows: 1) In order to solve the problem caused by MMC blocking in the DC distribution network, this study combines control and protection. The rapid increase of fault current could be limited by MMC active control, which makes fault identification more precise. Moreover, the protection and isolation scheme compensates for the shortcomings of the control strategy. The integration of control and protection schemes performs better than either of them individually, which not only avoids the short-term power outage but also accelerates the recovery of the system in the post-fault state.

2) According to the captured current zero-crossing features at the two ends of the line by an MMC active current limiting control, the faulty line can be identified quickly. The fault criterion is simple but credible, allowing it to work under different circumstances.

3) Based on the MMC active current limiting control, the coordination of DCCB and HSS can be utilized to complete the fault isolation. The number of DCCBs needed in this scheme reduces by half compared to that in the method of installing DCCBs at both ends of the lines. Moreover, the fault current provided by MMC with the active current limiting control is relatively small. Consequently, it lowers the demand for breaking the capacity of DCCB and further saves the cost of construction.

4) At present, protection and fault isolation schemes based on the MMC active control can only be applied to FBSM-MMC based flexible DC distribution networks. When it comes to active current limiting control scheme in HBSM-MMC based flexible DC distribution network, further studies need to be conducted.

\section{REFERENCES}

[1] L. Zhang, J. Liang; W. Tang; G. Li, Y. Cai and W. Sheng, "Converting AC Distribution Lines to DC to Increase Transfer Capacities and DG Penetration," IEEE Trans. Smart Grid, vol. 10, no. 2, pp. 1477-1487, March. 2019.

[2] S. K. Chaudhary, J. M. Guerrero, R. Teodorescu, "Enhancing the capacity of the AC distribution system using DC interlinks-A step toward future DC grid", IEEE Trans. Smart Grid, vol. 6, no. 4, pp. 1722-1729, Jul. 2015.

[3] T. H. Nguyen, K. A. Hosani, M. S. E. Moursi, and F. Blaabjerg, “An Overview of Modular Multilevel Converters in HVDC Transmission Systems With STATCOM Operation During Pole-to-Pole DC Short Circuits," IEEE Trans. Power Electron., vol. 34, no. 5, pp. 4137-4160, May. 2019.

[4] Y. Dong, J. Tang, H. Yang, W. Li and X. He, "Capacitor Voltage Balance Control of Hybrid Modular Multilevel Converters With Second-Order Circulating Current Injection," IEEE J. Emerg. Sel. Top. Power Electron., vol. 7, no. 1, pp. 157-167, March. 2019. 
[5] R. Li, L. Xu and D. Guo, "Accelerated switching function model of hybrid MMCs for HVDC system simulation," IET Power Electron., vol. 10, no. 15, pp. 2199-2207, Dec. 2017.

[6] R. Li, J. E. Fletcher, L. Xu, D. Holliday and B. W. Williams, "A Hybrid Modular Multilevel Converter With Novel Three-Level Cells for DC Fault Blocking Capability," IEEE Trans. Power Del., vol. 30, no. 4, pp. 2017-2026, Aug. 2015.

[7] L. Qu, Z. Yu, Q. Song, Z. Yuan, B. Zhao, D. Yao, et al., "Planning and analysis of the demonstration project of the MVDC distribution network in Zhuhai," Frontiers in Energy, vol. 13, pp. 120-130, 2019.

[8] X. Feng, Q. Xiong, D. Wardell, et al, "Extra-Fast DC Distribution System Protection for Future Energy Systems," IEEE Trans. Ind. Appl., vol. 55, no. 4,pp. 3421-3430, July. 2019.

[9] Wu, H. Li, G. Wang, and Y. Liang, "An improved travelling wave protection scheme for LCC-HVDC transmission lines," IEEE Trans. Power Del., vol. 32, no. 1, pp. 106-116, Feb. 2017.

[10] K. A. Saleh, A. Hooshyar and E. F. El-Saadany, "Ultra-High-Speed Traveling-Wave-Based Protection Scheme for Medium-Voltage DC Microgrids," IEEE Trans. Smart Grid, vol. 10, no. 2, pp. 1440-1451, March 2019.

[11] Y. Zhang, N. Tai, and B. Xu, "Fault analysis and traveling-wave protection scheme for bipolar HVDC lines," IEEE Trans. Power Del., vol. 27, no. 3, pp. 1583-1591, Jul. 2012.

[12] K. Jia, Z. Xuan, T. Feng, C. Wang, T. Bi, and D. W. P. Thomas, “Transient High-Frequency Impedance Comparison-Based Protection for Flexible DC Distribution Systems," IEEE Trans. Smart Grid, vol. 11, no. 1, pp. 323-333, Jan. 2020.

[13] M. Monadi, C. Koch-Ciobotaru, A. Luna, J. I. Candela, and P. Rodriguez, "Multi-terminal medium voltage DC grids fault location and isolation," IET Gener. Transm. Distrib., vol. 10, no. 14, pp. 3517-3528, Nov. 2016.

[14] P. Ruffing, N. Collath, C. Brantl, and A. Schnettler, "DC Fault Control and High-Speed Switch Design for an HVDC Network Protection Based on Fault-Blocking Converters," IEEE Trans. Power Del., vol. 34, no. 1, pp. 397-406, Feb. 2019.

[15] P. Ruffing, C. Brantl, C. Petino, A. Schnettler, "Fault current control methods for multi-terminal DC systems based on fault blocking converters," J. Eng., vol. 2018, no. 15, pp. 87-875, Oct. 2018.

[16] Guidelines for Typical Configuration and Power Supply Schemes of Middle Voltage DC Distribution Network, T/CEC 166-2018. Beijing: China Electricity Council, 2018.

[17] G. Jing, A. Zhang, H. Zhang, S. Sun, "Network topology and operation control of DC distribution network with AC DC converter," 2019 Chinese Control And Decision Conference (CCDC), Nanchang, China, 2019, pp. 6216-6220.

[18] S. Wenig, M. Goertz, C. Hirsching, M. Suriyah and T. Leibfried, "On Full-Bridge Bipolar MMC-HVDC Control and Protection for Transient Fault and Interaction Studies," IEEE Trans. Power Del., vol. 33, no. 6, pp. 2864-2873, Dec. 2018.

[19] S. Mirsaeidi, and X. Dong, "An Integrated Control and Protection Scheme to Inhibit Blackouts Caused by Cascading Fault in Large-Scale Hybrid AC/DC Power Grids," IEEE Trans. Power Electron., vol. 34, no. 8, pp. 7278-7291, August, 2019.
[20] J. Gao, X. Wang, F. Yang, "Current-limiting strategy based on PR controller and active power filter for droop controlled microgrid," $J$. Eng., vol. 2019, no. 16, pp. 2289-2295, March, 2019.

[21] G. Song, T. Wang, K. S.T. Hussain, "DC Line Fault Identification Based on Pulse Injection From Hybrid HVDC Breaker," IEEE Trans. Power Del., vol. 34, no. 1, pp. 271-280, Feb, 2019.

[22] R. Li, L. Yu and L. Xu, "Offshore AC Fault Protection of Diode Rectifier Unit-Based HVdc System for Wind Energy Transmission," IEEE Trans.Ind. Electron., vol. 66, no. 7, pp. 5289-5299, July. 2019.

[23] D. Jovcic, W. Lin, S. Nguefeu and H. Saad, "Low-Energy Protection System for DC Grids Based on Full-Bridge MMC Converters," IEEE Trans. Power Del., vol. 33, no. 4, pp. 1934-1943, Aug. 2018.

[24] H. Zhang, M. Wu, Y. Luo, G. Luo, J. He, R. Li, "A novel transientvoltage based fault protection method for VSC-MTDC systems," 2017 IEEE Conference on Energy Internet and Energy System Integration (EI2). Proceedings, Beijing, China, 2017, pp. 1-5.

[25] R. Li, L. Xu, D. Holliday, F. Page, S. J. Finney and B. W. Williams, "Continuous Operation of Radial Multiterminal HVDC Systems Under DC Fault," IEEE Trans. Power Del., vol. 31, no. 1, pp. 351-361, Feb. 2016.

[26] L. Qi; A. Antoniazzi, L. Raciti, "DC Distribution Fault Analysis, Protection Solutions, and Example Implementations," IEEE Trans. Ind. Appl., vol. 54, no. 4, pp. 3179-3186, July. 2018.

[27] R. Lazzari, L. Piegari, "Design and Implementation of LVDC Hybrid Circuit Breaker," IEEE Trans. Power Electron., vol. 34, no.8, pp. 73697380, Aug. 2019.

[28] L. Tang, B. T. Ooi, "Locating and Isolating DC Faults in MultiTerminal DC Systems," IEEE Trans. Power Del., vol. 22, no. 3, pp. 1877-1884, July. 2007.

[29] W. Xiang, S. Yang, L. Xu, J. Zhang, W. Lin and J. Wen, "A Transient Voltage-Based DC Fault Line Protection Scheme for MMC-Based DC Grid Embedding DC Breakers," IEEE Trans. Power Del., vol. 34, no. 1, pp. 334-345, Feb. 2019.

[30] J. Häfner, B. Jacobson, "Proactive hybrid HVDC breakers: a key innovation for reliable HVDC grids," CIGRE Bologna Symp. - Electr. Power Syst. Future: Integr. Supergrids Microgrids, Bologna, Italy, 2011, pp. 13-15.

[31] A. Hassanpoor, J. Häfner and B. Jacobson, "Technical Assessment of Load Commutation Switch in Hybrid HVDC Breaker," IEEE Trans. Power Electron., vol. 30, no. 10, pp. 5393-5400, Oct. 2015.

[32] Y. Ji, Z. Yuan, J. Zhao, et al, "Overall control scheme for VSC-based medium-voltage DC power distribution networks," IET Gener. Transm. Distrib., vol. 12, no. 6, pp. 1438-1445, March. 2018. 


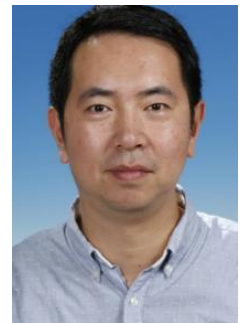

Tao Zheng (M'13) was born in Shandong, China, in 1975. He received the Ph.D. degree in power systems and automation from North China Electric Power University (NCEPU), Beijing, China, in 2005. He is currently a Professor with the School of Electrical and Electronic Engineering, NCEPU. His research interests are focused in the area of power system protection.

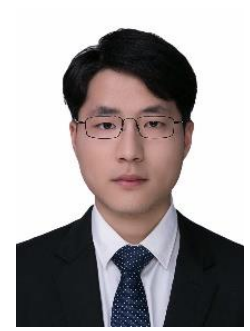

Wenxuan $\mathbf{L v}$ was born in Jiangsu, China, in 1996. He received a bachelor's degree in electrical engineering from North China Electric Power University, Beijing, in 2019. $\mathrm{He}$ is currently pursuing a master's degree in electrical engineering with North China Electric Power University. His research interest includes DC distribution system protection and control.

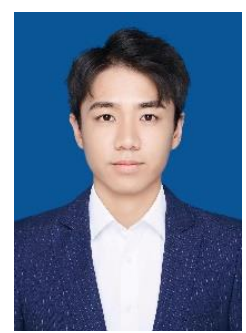

Qiong Wu was born in Liaoning, China, in 1995. He received a bachelor's degree in electrical engineering from North China Electric Power University, Beijing, in 2017. $\mathrm{He}$ is currently pursuing a master's degree in electrical engineering with North China Electric Power University. His research interest includes DC distribution system protection and control.

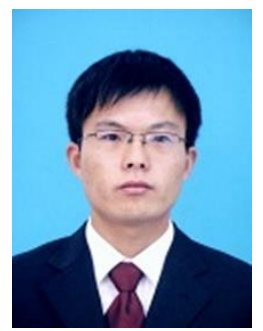

Rui Li (M'18) received the M.S. and Ph.D degrees in electrical engineering from Harbin Institute of Technology, Harbin, China, in 2008 and 2013, respectively. He is a researcher with University of Strathclyde in Glasgow, UK, since 2013.

His research interests include HVDC transmision systems, grid integration of renewable power, power electronic converters, and energy conversion.

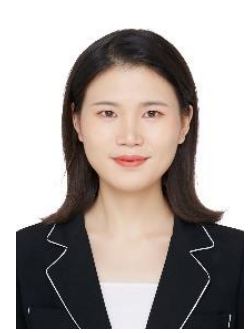

Xiaoxiao Liu (S'20) was born in Shanxi, China, in 1995. She received a bachelor's degree in electrical engineering from North China Electric Power University, Beijing, in 2018. She is currently pursuing a bachelor's degree in electrical engineering with North China Electric Power University. Her research interest includes protection for magnetically controlled shunt reactor and power transformer, control and protection of HVDC system.

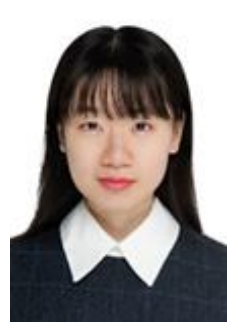

Chengqi Zhang was born in Jiangsu, China, in 1998. She is currently pursuing a bachelor's degree in electrical engineering with North China Electric Power University. Her research interest includes dynamic control of power electronics and autonomous power systems.

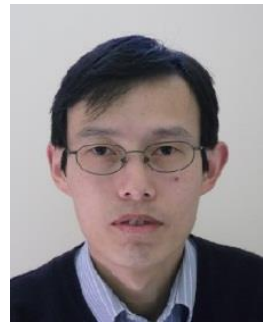

Lie Xu (M'03-SM'06) received the B.Sc. degree in Mechatronics from Zhejiang University, Hangzhou, China, in 1993, and the Ph.D. degree in Electrical Engineering from the University of Sheffield, Sheffield, $\mathrm{UK}$, in 2000.

$\mathrm{He}$ is currently a Professor at the Department of Electronic \& Electrical Engineering, University of Strathclyde, Glasgow, UK. He previously worked in Queen's University of Belfast and ALSTOM T\&D, Stafford, UK. His current research interests include power electronics, wind energy generation and grid integration, and application of power electronics to power systems. He is an Editor of IEEE Transactions on Power Delivery and IEEE Transactions on Energy Conversion. 